\title{
Article
}

\section{Evaluation of matron ward rounds to enhance patient experience and improve staff morale}

Mennin, Debbie and Moen, Charlotte

Available at http://clok.uclan.ac.uk/25475/

Mennin, Debbie and Moen, Charlotte (2019) Evaluation of matron ward rounds to enhance patient experience and improve staff morale. Nursing Management, 26 (3). pp. 22-25. ISSN 1354-5760

It is advisable to refer to the publisher's version if you intend to cite from the work. http://dx.doi.org/10.7748/nm.2018.e1762

For more information about UCLan's research in this area go to http://www.uclan.ac.uk/researchgroups/ and search for < name of research Group>.

For information about Research generally at UCLan please go to http://www.uclan.ac.uk/research/

All outputs in CLoK are protected by Intellectual Property Rights law, including Copyright law. Copyright, IPR and Moral Rights for the works on this site are retained by the individual authors and/or other copyright owners. Terms and conditions for use of this material are defined in the policies page.

\section{CLoK}

Central Lancashire online Knowledge www.clok.uclan.ac.uk

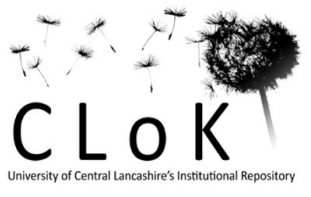




\title{
An evaluation of matron ward rounds to enhance patient experience and improve staff morale
}

\author{
Debbie Mennim, Charlotte Moen
}

Mennim D, Moen C (2018) An evaluation of matron ward rounds to enhance patient experience and improve staff morale. Nursing Management. doi: 10.7748/nm.2018.e1762

Peer review

This article has been subject to external double-blind peer review and has been checked for plagiarism using automated software

Correspondence

DMennim1@uclan.ac.uk

Conflict of interest

None declared

Acknowledgement

The authors would like to thank all at Liverpool Women's NHS Foundation Trust

Accepted

4 May 2018

Published online

Xxxxxx 2018

\begin{abstract}
Intentional rounding was introduced in the UK in 2012 to improve direct nursing care. Liverpool Women's NHS Foundation Trust (LWH) introduced intentional nursing rounds, called comfort rounds, in 2013, these are carried out and documented by nursing staff who check the patients in their care every two hours, particularly in relation to pain management, nutritional needs, hygiene and toilet needs and overall comfort. In September 2015 LWH introduced daily matron ward rounds (MWRs) following a directive from the trust's chief executive to provide assurance that comfort rounds were completed and that patient feedback was acted on in a timely manner. This article presents findings from an evaluation of the initiative and describes how daily MWRs have a positive effect on patient experience and staff morale but are resource intensive. Further qualitative research of their effect on staff morale and well-being, and patient experience, is recommended.
\end{abstract}

\section{Author details}

Debbie Mennim, leadership development (clinical leadership), lecturer, Faculty of Health, University of Central Lancashire, Preston, England; Charlotte Moen, senior lecturer, Faculty of Health and Social Care, Edge Hill University, Ormskirk, England

\section{Keywords}

management, matrons, patients, patient experience, patient feedback, service evaluation, quality assurance, ward organisation, ward rounds

Key points

- Daily matron ward rounds (MWRs) can have a positive effect on patients and staff, however they are resource intensive and the financial implications mean they may not be feasible. Daily ward rounds by ward managers and a monthly round by matrons, based on the principles and tool described in this article, may be a solution

- Patients appear to value the opportunity to raise concerns openly with a matron and seem confident the issues will be addressed, but it is difficult to evidence if daily MWRs enhance patient experience and there is lack of robust research to demonstrate this outcome 


\section{- Research is required to explore patients' views of the role of matrons and to determine if there is a link between staff morale/well-being and patient experience}

\section{Introduction}

Intentional rounding originated in the US as a proactive approach to improving patient care (Studer Group 2007). It was introduced in the UK in 2012 in response to recommendations by the prime minister to improve direct nursing care (Department of Health (DH) 2012a) and supported by the Releasing Time to Care Programme (NHS Institute for Innovation and Improvement 2010[Q1 Is this 2008?]) and endorsed by the Nursing and Care Quality Forum (2012). Along with other NHS trusts in England, Liverpool Women's NHS Foundation Trust (LWH) introduced regular intentional nursing rounds on all inpatient wards in 2013. These are called 'comfort rounds' at LWH and are carried out and documented by nursing staff on a two-hourly basis[Q2 Does this mean every two hours here?] for all inpatients. Comfort rounds are a formalised process where nursing staff conduct regular checks on the patients in their care, with a focus on pain management, nutritional needs, hygiene and toilet needs and overall comfort to improve patient experience (Fitzsimons et al 2011).

\section{Background}

Daily matron ward rounds (MWRs) at LWH were introduced in September 2015 following a directive from the chief executive to provide assurance to the trust that comfort rounds were being completed and patient feedback was acted on in a timely manner. The MWRs were in addition to the two-hourly comfort rounds completed by ward nursing staff and were undertaken by the matron, or deputy matron in their absence, every weekday excluding bank holidays. Initially the MWRs were a scoping exercise to determine if the comfort rounds were completed and to identify further actions. This demonstrated that rich information about patient experience could be captured through real-time patient feedback, however there was no formal tool in place to document this. So to capture this information a daily MWR tool was developed by the matron, deputy director of nursing and midwifery (DDNM) and head of audit.

The aim was to evaluate the effect of these daily MWRs in two gynaecology inpatient wards at LWH. The project was approved by the trust's research and development department and DDNM and received project registration from Edge Hill University Faculty of Health and Social Care Research Ethics Committee. Before starting the project ethical issues were considered in accordance with the Healthcare Quality Improvement Partnership guide (Brain et al 2011). The project used existing nationally validated patient and staff data collection processes and tools and did not therefore require ethical approval (NHS Research Authority 2016)[Q3 This does not appear in the reference list at the end. Please provide a reference].

A literature review was undertaken using Cinahl, Medline, Academic Search Premier Databases and the university's Discover More database to inform the project. However, this did not generate a significant amount of literature on the role of ward nursing staff undertaking regular intentional rounds, and no literature was identified on matrons undertaking regular ward rounds and the effect of this on patient experience and staff satisfaction

\section{Aims}

The aims of the project were:

» To enhance inpatient experience by providing patients with a regular opportunity for a one-to-one discussion with the matron to explore their experiences.

» To provide assurance to the trust's executive board that comfort rounds are completed.

» To explore nursing staff morale and to determine if they feel listened to, valued and supported.

\section{Methodology}

Kotter's (2012) change management framework was applied using an appreciative inquiry approach (Jones 2010, Richer et al 2010, Trajkovski et al 2013). Obtaining commitment from the ward managers was crucial and they welcomed the matron's regular presence on the wards from the outset.

A pivotal part of the project was to evaluate the effect of the MWRs on staff through the existing monthly staff survey, and this was an opportunity to engage with nursing teams on a diarised daily basis and increase visible leadership (Francis 2013). The MWRs provided instant patient feedback and matrons gave individual nurses feedback from patients at the end of each round (Goleman 2004). 
Over a five-month period (September 2015 to January 2016) data were collated on two wards, an oncology ward (Ward 1) and a benign gynaecological ward (Ward 2), from the Friends and Family Test (FFT), Patient Advice and Liaison Service (PALS), formal patient complaints, and the staff survey and completion of comfort rounds. Data were measured against information from a comparative five-month timeframe (September 2014 to January 2015).

\section{Findings}

\section{Project aim: to enhance patient experience}

Results from the FFT demonstrated that, apart from November 2015, scores remained consistently high on ward 1 (over 9.2 out of a maximum score of 10). FFT scores on ward 2 varied throughout the project but began to improve towards the end in comparison to the lowest score of 8.2 in October 2014 to approximately 9.7 in January 2016. There was a reduction in the FFT response rate on both wards during the project and it is possible that patients believed there was no need to complete the FFT card on discharge because the daily MWRs enabled them to give direct feedback about their care and experience.

Patient complaints are recorded in two formats at LWH, a PALS issue, which aims to resolve issues informally, and a formal written complaint. There was no difference in the number of complaints/PALS issues for either ward between September 2014 and January 2015, and September 2015 and January 2016. During the project, ward 2 received $80 \%(n=4)$ of the overall number of complaints/PALS issues and ward 1 received $20 \%(n=1)$. Ward 1 is an oncology ward and patients are admitted for longer periods which increases the opportunity for nursing staff to build relationships with patients. The Health and Social Care Information Centre (HSCIC) (2016) reported that complaints relating to clinical oncology are one of the lowest areas accounting for just $0.6 \%$ of all patient complaints. Ward 2 has a higher patient turnover and subsequently there are different demands on nursing staff due to the faster pace of working. Although the overall complaint numbers were low $(n=5)$ there was a peak during the winter months with an increase on ward $2(n=3)$ in November 2015 and on ward $1(n=1)$ in January 2016. The number of complaints/PALS issues received for ward 1 and ward 2 are displayed in Figures 1 and 2.

\section{Figure 1. The number of complaints/Patient Advice and Liaison Service (PALS) concerns received for ward 1}

\section{Figure 2. The number of complaints/ Patient Advice and Liaison Service (PALS) concerns received for} ward 2

These figures are not mirrored nationally as the HSCIC (2016) reported an increase in quarter two (July to September 2015). Quarter four data were not available at the time of writing. As LWH is a specialist trust the national winter bed pressures do not affect patient throughput and activity, so this could not have influenced the peak in complaints during this period. However, the reduction in activity due to the bank holidays required scheduling of extra theatre lists to maintain activity. The staff sickness rate on ward 1 in January 2016 was $1.65 \%$ which is well below the trust's threshold level of $3.5 \%$ and was therefore unlikely to have affected patient care and experience. Conversely, the sickness rate on ward 2 in November 2015 was $3.77 \%$ of which $65 \%$ was ongoing long-term sickness absence.

Francis (2013) identified that sickness absence rates affect patient outcomes while Maben et al (2012) reported a significant link between patient outcomes and staff well-being, therefore it is reasonable to consider that the reduced staffing levels on ward 2 might have contributed to the peak in PALS concerns/complaints in November 2015. It could be argued that the increased demand for activity combined with staff sickness during the winter months led to the peak in complaints.

Three of the four complaints received during the project from ward 2 were PALS issues generated through the daily MWRS and two were reported directly to the matron on her ward round, one of which became a formal complaint. The remaining PALS issue was described in a letter sent to the matron following the patient's discharge. The patient had written to the matron as a result of meeting her during their inpatient stay. While there was no difference in the overall number of complaints/PALS issues for ward 2, it is possible that the three PALS issues generated during the MWRs might not have been raised if patients had not had the opportunity to discuss them during the ward rounds.

Although one PALS issue became a formal complaint it is possible that raising concerns directly to a senior nurse prevented the other two from becoming formal complaints. It was clear that patients valued the opportunity and felt able to raise concerns openly with the matron which suggests the ward rounds enhanced patients' experiences. The patients who raised concerns during the ward 
rounds appeared confident that the issues would be addressed. However, it is difficult to evidence that the project has enhanced patient experience and there is an absence of robust studies to demonstrate this outcome (Forde-Johnston 2014).

\section{Project aim: to provide assurance that comfort rounds are completed}

Following the introduction of the MWRs the completion of comfort rounds was monitored from November 2015 to January 2016 using the daily MWR tool which captured the number of inpatients and the number of completed comfort round charts. The completion rates remained steady on ward 1 averaging at $97.3 \%$ and increased and plateaued on ward 2 in January 2016 at $92 \%$. There is no comparable data as compliance had not been robustly audited since the introduction of comfort rounds in 2013 . This suggests the daily MWRs contributed to the comfort round completion rates during the project.

\section{Project aim: to explore staff morale}

The trust undertakes a voluntary monthly anonymous staff survey and the overall response rate more than doubled from $3.6 \%$ to $7.6 \%$ during the project. This is largely due to the high response in September 2015 which yielded a combined response rate of 24 equating to $47.6 \%$ of staff across both wards. The annual NHS national staff survey (NSS) is launched in September and continues until the end of December. The trust encourages staff to engage with the NSS throughout September, therefore the increased response to the in-house staff survey in September 2015 could be attributed to this, although results from the September 2014 in-house survey do not reflect this. The daily MWRs also started in September 2015. It could be argued that as the 2014 NSS (NHS England 2015) reported lack of visible leadership as a concern among staff, the daily presence of a matron on the wards was an incentive for staff to engage with the local survey. This supports Alimo-Metcalfe and Alban-Metcalfe's (2008) engaging leadership style, adopted during the project.

The trust amended the staff survey questionnaire in August 2015, however there are similarities in the first seven questions in both surveys. Using the raw data and the seven similar questions it was possible to present comparable percentages of the amount of staff who responded positively, for example 'likely or extremely likely' and 'strongly agree or agree', to these questions between September 2014 and January 2015 and September 2015 and January 2016. During the project the positive responses ranged from 52.9\% to 88.2\% with marginal changes in percentage rates, the positive responses to four of the questions reduced a little, one stayed the same and two improved slightly. Due to the minimal changes in positive responses and the low response rate the differences are not statistically significant.

Positivity rates for the three questions in both surveys that are most pertinent to staff feeling valued and supported (Table 1) do not demonstrate a statistically significant change overall. However, it is encouraging to note that the positive response rate to the three questions (Figure 3) increased during the project from an average of 33.3\% in September 2014 to approximately $60 \%$ in September 2015 .

\begin{tabular}{|l|l|}
\hline \multicolumn{2}{|l|}{ Table 1. In-house staff survey questions that relate to staff feeling valued and supported } \\
\hline Staff survey used during September 2014 and January 2015 & Staff survey used during September 2015 and January 2016 \\
\hline $\begin{array}{l}\text { Q5. The people I work with treat me with respect [Q4 Should these all } \\
\text { be questions, eg Do the people you work with treat you with } \\
\text { respect? These questions all seem like the answers] }\end{array}$ & Q5. I am treated with respect by those I work with \\
\hline $\begin{array}{l}\text { Q6. I am able to make suggestions to improve the work of my } \\
\text { team/department }\end{array}$ & $\begin{array}{l}\text { Q6. I know what is going on in the organisation/department and have a } \\
\text { chance to contribute }\end{array}$ \\
\hline $\begin{array}{l}\text { Q7. We learn from mistakes and take action to prevent from happening } \\
\text { again }\end{array}$ & $\begin{array}{l}\text { Q7. As an organisation we learn from mistakes and take action to } \\
\text { prevent happening again }\end{array}$ \\
\hline
\end{tabular}

\section{Figure 3. Percentage of staff who responded positively to questions 5-7}

\section{Limitations}

The lack of reduction in patient complaints and PALS issues during the project suggests the MWRs may not have enhanced patient experience, although patients appear to value the opportunity to provide real-time feedback. This implies the tool used to measure the effect of the MWRs on patient experience is not fit for purpose, therefore it is difficult to evaluate the effect of the rounds on patient experience in depth. The current system does not allow for determining how soon after discharge the FFT cards are collated and there is no cut-off date for their return. It is also important to note that patient complaints can be submitted up to 12 months from the date of 
the event or 12 months from the date the patient or next of kin first became aware of it. It is therefore possible that complaints related to patient experience during the project may be generated in the future.

The significance of staff views is also limited due to the historically low response rate and lack of staff engagement in the in-house staff survey.

\section{Conclusion}

In May 2016 the Nursing Framework for England was launched by the chief nursing officer for England (NHS England 2016) and focuses on 'leading change and adding value' in everything we do as nurses to ensure patients have the best experience possible at every stage of their journey.

This project suggests that daily MWRs have a positive effect on patients and staff, however they are resource intensive and the financial implications must be considered. Due to increasing financial pressures on NHS trusts (Ham et al 2016) MWRs may not be feasible.

The matron recommends that ward managers undertake daily rounds and that she undertakes a monthly ward round using the main principles and tool used during the project. Further, as staff and patients appear to appreciate seeing the matron on the wards a qualitative research study should be undertaken to explore their views of the matron's role and to determine if there is a link between staff morale/wellbeing and patient experience.

\section{References}

Alimo-Metcalfe B, Alban-Metcalfe J (2008) Engaging Leadership. Creating Organisations That Maximise the Potential of Their People. Chartered Institute of Personnel and Development, London.

Brain J, Schofield J, Gerrish K et al (2011) A Guide for Clinical Audit, Research and Service Review. An Educational Toolkit Designed to Help Staff Differentiate Between Clinical Audit, Research and Service Review Activities. Healthcare Quality Improvement Partnership, England.

Carter B (2006) 'One expertise among many' - working appreciatively to make miracles instead of finding problems. Using appreciative inquiry as a way of reframing research. Journal of Research in Nursing. 11, 1, 48-63. [Q5 This is not cited in the article. Please cite or delete from references]

Department of Health (2012a) PM Announces New Focus on Quality and Nursing Care. Press release 6 January 2012. DH, London.

Department of Health (2012b) The NHS Friends and Family Test: Implementation Guidance. DH, London. [Q6 This is not cited in the article. Please cite or delete from references]

Fitzsimons B, Bartley A, Cornwell J (2011) Intentional Rounding: Its Role in Supporting Essential Care. www.nursingtimes.net/nursing-practice/clinicalzones/management/intentional-rounding-its-role-in-supporting-essential-care/5032316.article (Last accessed: 9 May 2018.)

Forde-Johnston C (2014) Intentional rounding: a review of the literature. Nursing Standard. 28, 32, 37-42.

Francis R (2013) The Mid Staffordshire NHS Foundation Trust Public Inquiry. Report of the Mid Staffordshire NHS Foundation Trust Public Inquiry. The Stationery Office, London.

Goleman D (2004) Working with Emotional Intelligence. Bloomsbury, London.

Ham C, McKenna H, Dunn P (2016) Tackling the Growing Crisis in the NHS: An Agenda for Action. www.kingsfund.org.uk/publications/articles/nhs-agenda-for-action (Last accessed: 9 May 2018.)

Health Research Authority (2016) Assessment Criteria and Standards Document.

file:///C:/Users/User/AppData/Local/Packages/Microsoft.MicrosoftEdge 8wekyb3d8bbwe/TempState/Downloads/hra-approval-assessment-criteria-standardsdocument.pdf [Q7 This is not cited in the article. Please cite or delete from references. The link is also not working, can you please provide a new link if this is to be referenced.](Last accessed:15 May 2018.)

Health and Social Care Information Centre (2016) Data on Written Complaints in the NHS 2015/16 Quarter 3. Experimental Statistics. HSCIC, England. Jones R (2010) Appreciative inquiry: more than just a fad? British Journal of Healthcare Management. 16, 3, 114-122.

Kotter J (2012) Leading Change. Harvard Business Press Review, Boston MA. [Q8 This is not cited in the article. Please cite or delete from references]

Maben J, Peccei R, Adams M et al (2012) Exploring the Relationship Between Patients' Experiences of Care and the Influence of Staff Motivation, Affect and Wellbeing National Institute for Health Research, London.

NHS England (2015) Staff Survey 2014 - Detailed Spreadsheets. www.nhsstaffsurveys.com/Page/1042/Past-Results/Staff-Survey-2014-Detailed-Spreadsheets (Last accessed: 25 October 2018.) 
NHS England (2016) Leading Change, Adding Value. A Framework for Nursing, Midwifery and Care Staff. NHS England, Redditch, England.

NHS Institute for Innovation and Improvement (2010)[Q9 Is this 2008?] Releasing Time to Care: The Productive Ward. NHS Institute for Innovation and Improvement, England.

Nursing and Care Quality Forum (2012) Letter to the Prime Minister. www.gov.uk/government/uploads/system/uploads/attachment_data/file/216812/NCQF-letter-toPM.pdf (Last accessed: 9 May 2018.)

Richer M, Ritchie J, Marchionni C (2010) Appreciative inquiry in health care. British Journal of Healthcare Management. 16, 4, 164-172.

Studer Group (2007) Hourly Rounding Supplement. The Studer Group, Pensacola FL.

Trajkovski S, Schmied V, Vickers M et al (2013) Implementing the 4D cycle of appreciative inquiry in health care: a methodological review. Journal of Advanced Nursing. 69, 6, 1224-1234. 
Figure I. Number of complaints and patient advice and liaison service concerns received about ward I

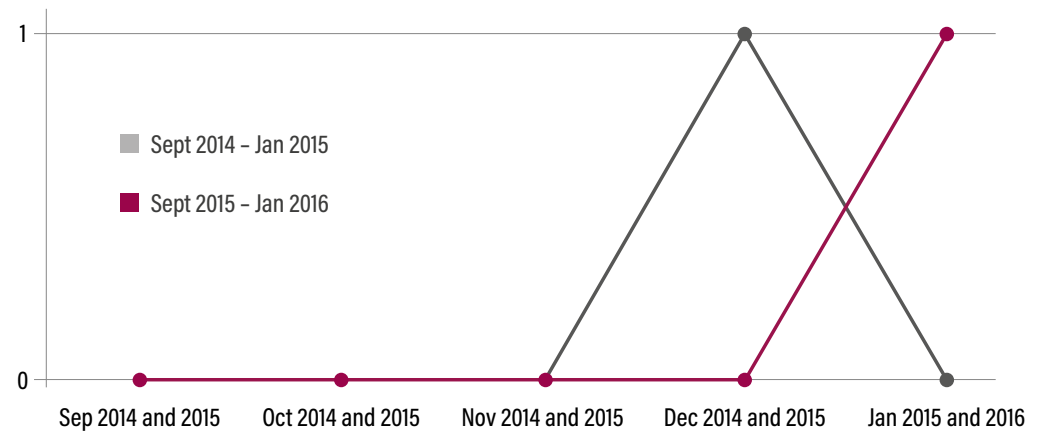

[Q10 I don't really undertand how this figure has one axis running from Sept 2014 to Jan 2016, but the key to the lines has different years. Please check] 
Figure 2. Number of complaints and patient advice and liaison service concerns received about ward 2

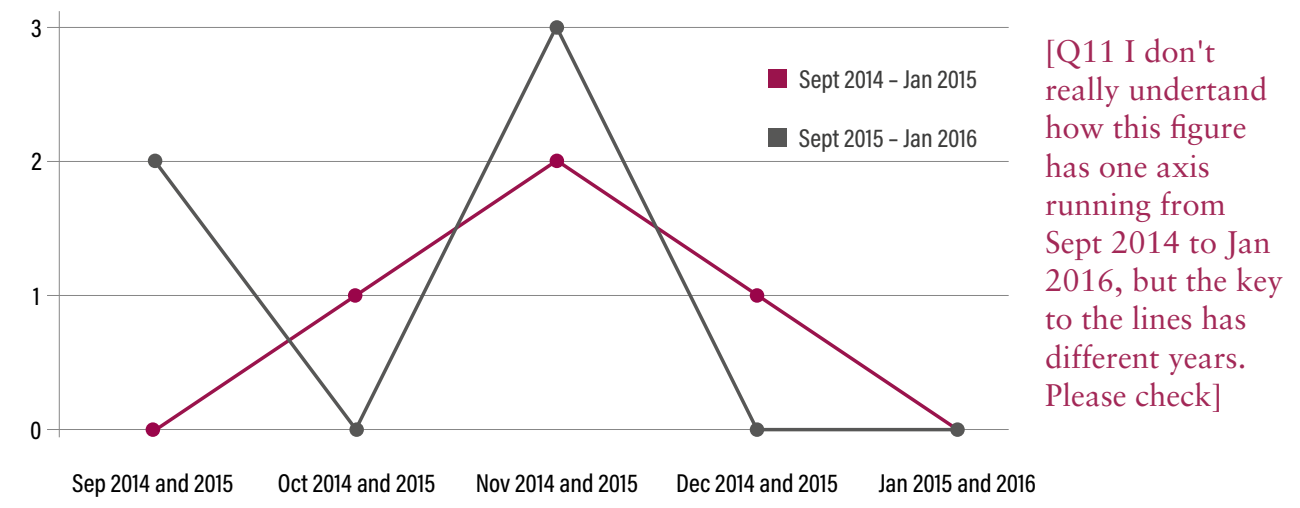


Figure 3. Percentages of staff who responded positively to questions 5, 6 and 7 in September 2014 and September 2015

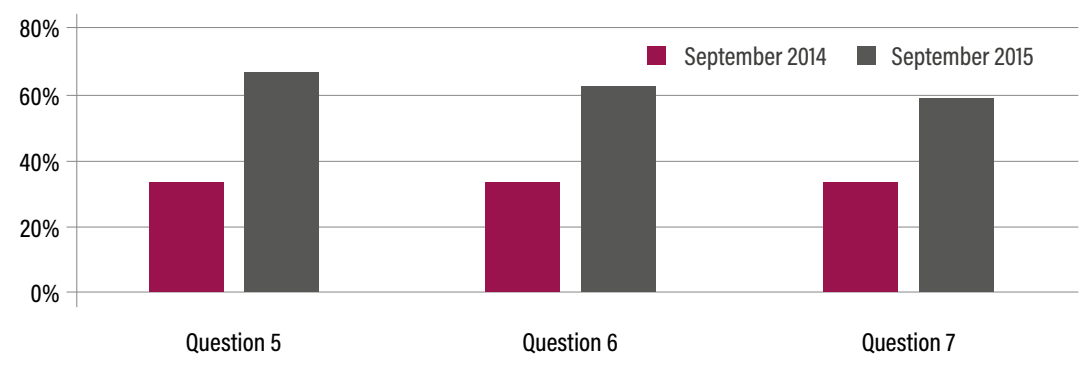

